\title{
DUPLO RECONHECIMENTO: \\ A ROLAND BARTHES, NO CENTENÁRIO DE SEU NASCIMENTO E A AGUSTÍN ESCOLANO BENITO, POR OCASIÃO DO TÍTULO DE DOUTOR HONORIS CAUSA \\ DOI: http://dx.doi.org/10.1590/2236-3459/57718
}

Maria Stephanou, coeditora

Sob a história, a memória e o esquecimento.

Sob a memória e o esquecimento, a vida. Mas escrever a vida é outra história.

Inacabamento.

Paul Ricoeur

istória. Sucedeu ao último número 46 de História da Educação,
homenagearmos Jacques Le Goff, autor de tramas entre história e memória.
Este número 47 se volta, igualmente e pelo dever de memória, a render homenagens, desta vez um duplo reconhecimento.

Memória. Reconhecimento a um grande pensador do século XX, cujo centenário do nascimento comemoramos em 2015: Roland Barthes (Cherbourg, França, 12 de Novembro de 1915 - Paris, França, 26 de Março de 1980), escritor, semiólogo, filósofo, sociólogo e crítico literário francês.

Vida. Homenagem a um dos mais importantes pesquisadores do campo da História da Educação da atualidade, de reconhecimento internacional, Agustín Escolano Benito (Berlanga do Douro, Soria, Espanha, 1941), professor, escritor, filósofo, pesquisador espanhol.

Dois pensadores, dois autores dedicados à arte da escritura, cientes do inacabamento. Ousamos aproximá-los, sem os artifícios dos supostos encontros, de sincronias ou implicações recíprocas. Simplesmente, diferentes movimentos do pensamento nos levaram a evoca-los aqui para o duplo tributo: o tempo da cronologia cedeu lugar ao tempo que se faz oportuno e que leva a coincidir as evocações de seus nomes.

Peter Burke, em artigo publicado na Folha de São Paulo dos idos de 1998 (Burke, 1998, p. 53), escreveu que o hábito de festejar datas só surgiu com a ciência quantitativa do século 17, porque parece ter sido neste século que, sob influencia do luteranismo alemão, aboliu-se o culto aos santos e elegeu-se um substituto: um centenário oferecia uma espécie de canonização de um evento, como o centésimo aniversário das "Noventa e Cinco Teses" de Lutero, na Alemanha protestante, ou em 1640, em Leipzig, as 
comemorações aos 200 anos da invenção de Gutenberg. Burke ressalta que "por volta do século 18, centenários, bicentenários eram regularmente celebrados na Alemanha, França e Inglaterra, comemorando, por exemplo, os nascimentos de Shakespeare e Voltaire", e assim por diante. Para Burke, o aparente consenso dos séculos 17 a 19 parece ter sido substituído, no século 20, por debates e conflitos: celebrar ou simplesmente comemorar? Para evitar uma celeuma infindável, propomos aqui uma imersão no momento da oportunidade, aquela que ancorada no tempo presente, nos leva a render homenagem a Barthes e, simultaneamente, registrar à comunidade de pesquisadores brasileiros para que venha a se somar ao elogio prestado pela Universidade de Lisboa a Agustín Escolano, que recentemente concedeu-lhe o título de Doutor Honoris Causa. Como diria Benjamin, estamos imersos num tempo saturado de agoras (Benjamin, 1987, p. 229).

Agora, Barthes homenageado por ocasião de uma contagem que, embora quantitativa - o centenário - mostra-se oportunidade ímpar para registros, evocações, provocações ao pensamento. Roland Barthes é pensador que indiscutivelmente nos incita ao desassossego, ou em suas palavras, faz-nos pulsar o coração: medo, gozo, erupção da alteridade (Barthes, 1977). Aos leitores que não percorreram quaisquer de suas escrituras, fica o convite a enveredarem por entre suas astutas oscilações, instigadoras da pulsão chamada precariamente de curiosidade.

Pode parecer mera coincidência, palavra astuciosa que sugere conexões improváveis entre vários ardis da linguagem, mas também neste numero 47 oferecemos aos leitores uma Sessão especial, que publica com ineditismo no Brasil a Aula magna de Agustín Escolano, cuja apresentação proferida pelo pesquisador e professor português Justino Magalhães, dispensa quaisquer outros parágrafos de destaque à importância de Escolano no campo da História da Educação. Sessão Especial brinda os leitores, assim, com dois textos de exímia escritura. A esta soma-se um dossiê, Imagem e cultura visual em História da Educação, integrado por cinco artigos. Sessão Especial e dossiê, de certa maneira, evocam intensamente distintas contribuições de Barthes ao pensamento contemporâneo: Aula, escritura, leitura, fotografia ${ }^{1}$.

Barthes foi escritor e autor reconhecido, como também controvertido, em seu tempo. Muitas paixões, polêmicas e críticas o acompanharam, assim como o sucederam e persistem em nossos dias, o que é bem provável que confirme seu pensamento cortante e, como ele mesmo se descrevia, próprio de um sujeito impuro. Professor no Collège de France, instituição que ele considerava uma das últimas astúcias da História, inaugurou, a 7 de janeiro de 1977, a cadeira de semiologia literária, cuja aula intitulada Leçon (Barthes, 1978), teve o texto publicado pela primeira vez em 1978, tornando-se célebre e por muitos considerado o ponto de partida para a "aventura semiológica" que Barthes desenvolveu e escreveu com ousadia.

Temos, então, neste número 47, tramas de muitas linguagens e línguas, urdidas na, com a, para a, em intersecção ou no coração da História da Educação. Como sugere Barthes, "o sujeito chega à fruição pela coabitação das linguagens" (Barthes, 1987).

\footnotetext{
${ }^{1}$ Apenas para registro das contribuições do autor nesses domínios, podemos citar dentre suas muitas obras, algumas publicadas no Brasil: Língua, discurso e sociedade, Global Universitária; $A$ câmara clara, Nova Fronteira (2000); O prazer do texto, Perspectiva (2002); O rumor da língua, Martins Fontes (2004); O grau zero da escrita, Martins Fontes (2004).

Hist. Educ. [Online] Porto Alegre

v. 19

n. 47

Set./dez., 2015

p. $7-12$
} 
Coabitação dos idiomas, dos campos empíricos que operam com diferentes linguagens, verbais e não-verbais, das teorias, das temporalidades em jogo. À leitura, como propõe Barthes, incumbe criar formas únicas, formas virtuais do texto ativadas pela imaginação do leitor.

Quanto aos artigos deste número de História da Educação, o leitor pode eleger a sucessão, a inversão, o saltitar das páginas, os artigos a lançar vista d'olhos ou a imergir, e, quem sabe, aqueles a manter adormecidos nas estantes ou nas páginas web. $O$ Sumário apresenta uma (dis)posição que inicia pela Sessão Especial, composta pelo texto Honoris causa: elogio de Agustín Escolano Benito, de Justino Pereira Magalhães acompanhado do discurso proferido por Agustín Escolano Benito, no ato de investidura como Doutor Honoris Causa pela Universidade de Lisboa que concedeu-Ihe tal distinção. Ambos foram proferidos em 23 de abril de 2015, na Universidade de Lisboa.

Segue-se o dossiê Imagem e cultura visual em História da Educação, organizado e apresentado pela pesquisadora da Universidade Federal do Rio Grande do Sul, Profa. Dra. Zita Rosane Possamai, que oferece um conjunto de artigos com instigantes reflexões e notas teórico-metodológicas sobre fotografias, nova objetividade \& Nova Pedagogia; educação e espetáculo no cinema científico; usos da fotografia pública; relações entre fotografia e textos na imprensa de variedades; corpos escolares em imagens do espaço urbano. O dossiê, assim, reúne investigações do Professor Olivier Lugon, da Universidade de Lausanne, Suíça, da Professora e pesquisadora Andrea Cuarteolo, da Conicet/Universidad de Buenos Aires, Argentina, da historiadora e professora da Universidade Federal Fluminense, dra. Ana Maria Mauad, do Professor Cláudio de Sá Machado Júnior, da Universidade Federal do Paraná, e da própria organizadora do dossiê, Zita Possamai. Os cinco artigos apresentam objetos e documentos pouco ou desconhecidos da pesquisa em História da Educação, e de certa forma sinalizam a fecundidade de que venham a ser (re)visitados, (re)descobertos, eleitos como centrais e privilegiados em estudos dessa área. A cultura visual, como constructo teórico, aproxima transversalmente estes artigos e, em alguma medida, irradia o espectro ampliado das idéias que compartilham ${ }^{2}$. Vale percorrer suas escrituras e surpreender-se com os achados, sobretudo as pistas para outras pesquisas a serem empreendidas, quiçá por jovens pesquisadores ainda em busca de temas instigantes ${ }^{3}$.

$\mathrm{Na}$ continuidade, sete artigos e uma resenha abordam temáticas bastante contrastantes e períodos da História da educação dos séculos 19 e 20. Pesquisadores de diferentes instituições nacionais e do exterior contemplam contextos sociohistóricos da educação de diversos países, Chile, Portugal, Argentina e Brasil.

Do Chile à Argentina: renovação pedagógica é questão central no artigo de Jaime Caiceo Escudero, da Universidade de Santiago do Chile, que parte de informações biográficas sobre Patricio Cariola para demonstrar, no contexto da História da Educação chilena e latino-americana, a contribuição de sua ação pedagógica, mesmo em tempos de ditadura. Contribuição à história do ensino superior e compreensão das políticas educativas na Argentina é a direção do artigo de Mariana Mendonça, ligada à

${ }^{2}$ Fica o registro de que Barthes, aqui homenageado, está referido no texto de Claudio Sá neste dossiê (Barthes, 1990).

${ }^{3}$ Que tal pensarmos, como sugere Renato Janine Ribeiro, na leitura, quer dos clássicos da área, quer dos referenciais importantes, como prática que recupere o senso da aventura face ao desconhecido? (Ribeiro, 1999). 
Universidade Nacional de General Sarmiento. Examina o diagnóstico feito pelo Setor de Educação do Conselho Nacional de Desenvolvimento da Argentina, anos 1960, e suas repercussões nas políticas universitárias adotadas, as idéias de desenvolvimento, a massificação do acesso e os resultados deficientes na formação de recursos humanos na Argentina.

De Portugal ao Brasil: Maria Manuela Pereira Figueiredo Rodrigues, pesquisadora vinculada à Universidade de Lisboa, reconstrói, na tessitura das memórias, dos documentos escritos e manuscritos, aquilo que conceitualiza como o "lado lúdico da escola", os tempos que escapam das lições. Afirma que a escola pode ter sido muito mais que submissão e controle, pois a vida pulsava nos recreios, habitados por jogos e brincadeiras infantis. Sim, estes tiveram lugar no universo escolar. A História da educação no Brasil é examinada a partir de quatro artigos: educação de surdos, feminização do magistério, educação e religiosidade, instituição educativa confessional batista.

Pedro Henrique Witchs e Maura Corcini Lopes, ambos vinculados à Universidade do Vale do Rio dos Sinos abordam a governamentalidade, conceito foucaultiano, para propor uma espécie de governamento linguístico, que consistiu na instauração de processos de condução/normalização e difusão da língua portuguesa escrita e da língua brasileira de sinais entre os surdos durante o Estado Novo. André Paulo Castanha, da Universidade Estadual do Oeste do Paraná, argumenta a intersecção entre dois processos: feminização do magistério e coeducação; discursos e legislação. Analisa, para isso, discursos de intelectuais, professores e autoridades que defendiam a prática da coeducação nas escolas públicas primárias, e como reverberaram na legislação educacional de meados do século 19. Compara ações implantadas na Corte e nas províncias do Rio de Janeiro, Mato Grosso. Para o autor, os debates e encaminhamentos em torno da coeducação jogaram um papel fundamental no processo de feminização do magistério. Patrícia Weiduschadt, da Universidade Federal de Pelotas, acompanha os movimentos da instituição luterana do Sínodo de Missouri no sul do Brasil naquilo que permitem observar das relações entre educação e religiosidade na primeira década do século 20 . $O$ artigo de Taciana Brasil dos Santos, ligada à Universidade Federal de Minas Gerais, de certa forma também tematiza educação e religião: é uma instituição educativa confessional batista inaugurada em Belo Horizonte pelos protestantes norte-americanos que recebe sua atenção. Argumenta o quanto a educação escolar foi uma das principais formas de difusão da mensagem desta corrente religiosa.

Na seção Resenha, Cassiane Curtarelli Fernandes, ligada à Universidade de Caxias do Sul, Brasil, propõe a leitura de uma obra que coloca em intersecção infância, imigração e escola, cujo título é Bambini brasiliani: a infância das crianças italianas e ítalobrasileiras, organizado por Eliane Mimesse, com apresentação de Marta M. Chagas de Carvalho, publicado pela Editorial Paco, Brasil, em 2013.

Por fim, não menos importante, nossa revista inaugura uma nova sessão, em verdade a sessão Documentos redimensionada para que consista em sessão Acervos e documentos. A idéia da editoria é ampliar e potencializar a circulação de informações sobre acervos documentais, a exemplo da reprodução de documentos raros até então realizada. Nosso intuito maior continua sendo o de disseminar, com vistas à fomentar a socialização de achados, de esforços de preservação e constituição de acervos, além de difundir possibilidades de acesso a pistas e indícios disponíveis para, quiçá em um futuro 
muito próximo, ver multiplicadas diversas investigações bem fundamentadas, empreendidas por seus leitores, em sua maioria pesquisadores do campo de estudos da História da Educação. A excelente apresentação da nova sessão Acervos e documentos, elaborada por Maria Teresa Santos Cunha, da Udesc, Brasil, sublinha que organizar e salvaguardar em acervos o denominado patrimônio cultural, histórico e educativo, constitui-se, no tempo presente, como uma mudança epistemológica marcada pela ascensão da dimensão memorial da vida escolar. Trata-se, pois, de movimentos de história, memória \& vida, e, sobretudo através de sua publicização como nesta sessão, consiste em boa estratégia para fomentar outras práticas preservacionistas. São sete os acervos do Rio Grande do Sul apresentados em seis textos. Quatros ligados a universidades e 3 ligados a instituições educativas, a saber: universidades: 1) o grupo de pesquisa História da Alfabetização, Leitura, Escrita e dos Livros Escolares da Universidade Federal de Pelotas, Brasil; 2) Centro de Documentação - parte constitutiva do Centro de Estudos e Investigações em História da Educação -, ambos também da Universidade Federal de Pelotas, Brasil; e de instituições escolares, a saber: 4) o Museu Escolar Arnildo Hoppen, do Colégio Sinodal de São Leopoldo, RS, Brasil; 5) o Memorial do Deutscher Hilfsverein, do Colégio Farroupilha, Porto Alegre, RS, Brasil; 6) Museu do Colégio Municipal Pelotense, Pelotas, Brasil; 7) Museu e Arquivo Histórico La Salle, Universidade La Salle, Canoas, Brasil.

Agustín Escolano, em seu discurso de honoris causa, sublinha que há várias décadas os investigadores portugueses e espanhóis convivem abertos a uma comunicação fluida entre pares e que é a partir deste espírito de convívio que interpreta a outorga da distinção recebida. Nós, editores da Revista História da Educação, pensamos que o reconhecimento alcançado é mais que um generoso gesto de amizade, embora esta esteja indiscutivelmente presente, mas é insuficiente por si só. O professor Justino Magalhães demonstra em títulos e números a grande contribuição do professor Escolano para o campo da História da Educação em nível internacional. Foi uma honra para nós, em 2011, termos sido brindados com a possibilidade de publicar o artigo Más allá del espasmo del presente: la escuela como memoria de sua autoria.

Professor Escolano, permita, também, que possamos tomar de empréstimo suas palavras, acima referidas, para dizermos que há pelo menos três décadas, investigadores portugueses, espanhóis e brasileiros da História da educação convivem abertos, fazem circular saberes e fazeres historiográficos, atravessando o Atlântico, e nossa revista têm sido um espaço ímpar, precursor e constante, de difusão mútua de nossos estudos históricos.

Como convite à leitura, reprisamos aquelas palavras inspiradoras, inúmeras vezes pronunciadas desde que Barthes as tornou públicas, e que se voltam às (im)possibilidades de instituir um certo jeito de viver o saber: "nenhum poder, um pouco de saber, um pouco de sabedoria e o maior sabor possível" (Barthes, 1987).

\section{Referências}

BARTHES, Roland. Aula. São Paulo: Cultrix, 1978. 
BARTHES, Roland. O prazer do texto. São Paulo: Perspectiva, 1987.

BARTHES, Roland. O óbvio e o obtuso: ensaios críticos III. Rio de Janeiro: Nova Fronteira, 1990.

BENJAMIN, Walter. Magia e técnica, arte e política. Obras Escolhidas, v. 1. São Paulo: Brasiliense, 1987.

BURKE, Peter. O descobrimento do tempo. Folha de São Paulo, São Paulo, 25 jan. 1998. RIBEIRO, Renato Janine. Não há pior inimigo do conhecimento que a terra firme. Tempo Social; Rev. Sociol. USP, S. Paulo, 11(1): 189-195, 1999. 